\title{
Towards a socio-structural framework for life course analysis
}

\author{
René Levy, University of Lausanne, Switzerland \\ Felix Bühlmann, University of Lausanne, Switzerland
}

\begin{abstract}
In spite of several decades of development, the theoretical underpinnings of life course research go rarely beyond the five general principles formulated by Elder. This article proposes a socio-structural framework based on a definition of the life course as an individual movement through social space. It integrates structural and cultural aspects, but gives priority to the former, and considers social space to be defined by three basic dimensions of differentiation: hierarchical ranks, specialisation, and system levels. In a second part, we discuss how Elder's principles relate to and can be used in the framework we propose. Since several disciplines are interested in this topic, our approach includes a series of docking points not only for other theoretical perspectives from sociology, but also from other disciplines such as social psychology or political science.
\end{abstract}

Keywords: life course - social stratification - social mobility - gender - agency - institutionalisation

\section{Introduction : life-course research, life-course paradigm, life-course theory}

Life-course research has developed considerably in the last decades and become a multidisciplinary phenomenon, including such disciplines as sociology, social and developmental psychology, demography, history, economics, and others (Mortimer and Shanahan, 2006; Heinz, Huinink and Weymann, 2009). In line with its recent evolution, it has no explicit and encompassing theory, but scholars frequently refer to the life-course paradigm or life-course approach, generally identified with the five heuristic principles Elder repeatedly presented (e.g., Elder 1995; Elder, Kirkpatrick Johnson and Crosnoe 2003, Alwin 2012). These principles are sufficiently oecumeni- 
cal to not exclude any more stringent theoretical or disciplinary stance. This justifies their identification as a paradigm rather than a theory, but also limits their analytical grasp as they remain very broad and unspecified. They tell us how we should look at social reality when we are interested in the life course without offering an explicit conceptual framework. The present article proposes some basic elements of a more elaborated conceptual framework for life-course research. It offers many docking points for other theoretical and disciplinary approaches, but is built from a strong, though not exclusive, sociological basis. More specifically, we try to conceptually articulate the structural landscapes with the individual trajectories traversing them. We spell out the mechanisms of institutional influence that shape life courses, including an account of different types of institutions and their functioning. In a second part, Elder's five principles will be used as illustrating search lights to test our framework's aptitude to cover and analyse the conceptual space these principles embrace.

\section{Elements of a sociological framework for life-course research}

How to analyse life courses sociologically?

Directing the focus on the relation between life courses and the life-course passengers' social environment is certainly a central feature of a sociological approach to life courses. This focus is present in many definitions of the life course concept. Take the example of Mitchell (2003, citing Giele \& Elder, 1998, p. 22). She states that the life course is "a sequence of socially defined events and roles that the individual enacts over time" and adds that "these events do not necessarily proceed in a given sequence, but rather constitute the sum total of the person's actual experience." 1 However, this definition - as many others in the literature - remains concentrated on an

\footnotetext{
${ }^{1}$ Other definitions rely on the life-courses' age-gradedness (Elder, Johnson \& Crosnoe 2003, Shanahan \& MacMillan 2008). We prefer not to postulate age as the basic structural (or structuring) element of life courses in a sociological perspective, but as a socially constructed corrollary whose signification depends on the specific societal institutionalisations of life courses in a given society. We explain this perspective in our section about life-course standardisation.
} 
individual's journey. But a journey through what landscape? Socially defined events and roles are not just out there to be taken up idiosyncratically by an individual to enact them. Individuals act in social contexts, and these contexts are made up not only by other people interacting with each other. This idea is basic for a sociological outlook, but has also been formulated, for instance, by Bronfenbrenner (1979) for his social-psychological perspective. He not only postulated the contextual embeddedness of individuals' development, but already differentiated "context" into micro-, meso- and macroscopic levels. Contexts are located on different systemic levels and they are organised in specific ways. They have a (spatialized and historical) structure in which individuals occupy positions that are to a considerable extent constitutive for the array of ambitions and opportunities these individuals find within their reach. In order to indicate the socially structured character of actors' contexts, we propose to define life courses as people's movements through social space. In modern societies social space is organised in a multiplicity of social fields that are more or less differentiated from each other and internally structured (Bourdieu 1975; Lewin 1951; see also more recently Martin 2003, Fligstein \& McAdam 2012).2 If we take into account the parallel existence of various social fields with their own internal structures and the fact that individuals can participate in those fields, we can conceptualise life courses as movements through social space.

\section{Social fields and their structure}

We use the term "social field" in a rather general sense, as a bounded, partly autonomous ensemble of interactions that share some kind of specificity. The main implication of the field concept is that whatever kind of actors are part of it, they do not act in isolation but in direct or indirect interaction with each other. It is in this very general sense that Lewin (1951) has introduced what he called "field theory in

\footnotetext{
${ }^{2}$ In the theoretical context of this paper the notions of field and of system are very close to each other and might be treated as synonyms. We prefer the notion of field because it has fewer theoretical implications that would have to be discussed at some length.
} 
social science". We find the same idea already in Weber's (1972: 11) definition of so-

Internal structure of social fields: Each social field has its own (internal) structure which is generally organised along two basic dimensions of differentiation: "vertical" hierarchy and "horizontal" division of labour (or segmentation, or institutional sectors, etc.). Both these dimensions are key for the analysis of any kind of social structure. They are treated by a vast literature that we do not aspire to adequately comment in this article, but that finds here an important entry point into our framework. Historical changes in these dimensions directly or indirectly impact on individuals' possibilities of action by changing their opportunity structures and also the ambitions of movement they can aspire to.

Between-field structure and systemic differentiation: Contemporary societies are composed of a series of social fields, some of which have been called institutional sectors. Fields are, of course, differentiated from each other by mutual boundaries that may be more or less porous - often differentially so according to the type of inter-field exchanges or interactions, or according to the kind of interacting actors. Another, less frequently treated aspect is systemic or system-level differentiation. Social fields are mostly part of more encompassing, even international regions or associations forming in their turn social fields that form together the global world order. In other words, fields are also organized along a third basic dimension that we call systemic differentiation (Bourdieu, 1993). This dimension of differentiation extends between the extremes of small microsocial groups, including, for instance, couples, up to the most macrosocial level that some authors term world society, others world (social) system (Atkinson, 2014; Heintz and Greve 2005). In this sense, "smaller" or lowerlevel fields, e.g., teams, are often part of a more encompassing, higher-level field such as an organisation. And organisations are often themselves parts of even more en-

\footnotetext{
${ }^{3}$ Recall Weber's illustration by two biking situations. If two bikers travelling in opposite directions cross and avoid carefully touching each other, this is an instance of social behaviour in Weber's sense. If they bump into each other, it is an accidental event, but no social behaviour (unless they do it on purpose).
} 
compassing fields, e.g., a national or international industry, etc. ${ }^{4}$ Organisations are a specific, particularly formalised kind of social field; many fields are much less formally organised, down to vaguely bounded and mainly informal fields, such as networks or social movements.

An author who has amply referred to the notion of social fields is Bourdieu (1975). He defines fields as systems of relations between positions which are differentially endowed with volumes and forms of capital. These forms of capital represent dimensions of hierarchical (vertical) differentiation specific to the field and are the central stake of social competition within the field (in a more Weberian terminology, one could speak of a central social good). Individual actors' behaviour in a given field is supposed to be strongly influenced by their positions and the positional competition just mentioned. According to Bourdieu, capital is the set of resources which individuals inherit (mainly from their family), acquire during their biographical trajectory, or convert into each other during biographically critical events, transitions or turning points (Pallas and Jennings, 2009). The most important and in a certain sense general forms of capital are economic, cultural and social capital (Bourdieu, 1986). These types of capital, even if they have specific logics and timings of accumulation and acquisition, are relatively well transferable between different fields. But every field, e.g., the field of the family, the artistic field or the political field, can also have its specific form of capital which is important in this field but cannot easily be transferred to another field (for a critical view on this, see Neveu, 2013).

While in most of the field-theoretical literature the focus has been on dynamics within one given (and more or less autonomous) field, Fligstein and McAdam explicitly also deal with interactions between fields. They distinguish between at least two different dimensions of interactions between fields: fields can first be more or less close. Whereas distant fields do not influence each other and have no ties, proximate fields

\footnotetext{
${ }^{4}$ Fligstein \& McAdam (2012) use the metaphor of Russian dolls. As most metaphors, it is appealing, but cannot tell the whole story as it illustrates only the relation of a (sub-)system being contained in a higher-order system. However, it does not include the fact that in most cases, there is more than one system on the same systemic level: there are several teams in a firm or in one of its divisions, there are several provinces in a state, there are several classes in a school, etc., and the relations of those units sharing the same system level are themselves subject to vertical and horizontal differentiation.
} 
are regularly in contact and do influence each other. In a life-course perspective, the family field and the employment field are doubtlessly very close and are related by recurrent and routinized interaction. Another form of closeness and type of tie exists between fields in which participation is typically subsequent, as between formal education and employment. Second, these authors distinguish between dependent and interdependent fields. A field is dependent on another if it is hierarchically subordinated to it; interdependence on the other hand describes situations where fields exercise a more or less equal influence over each other. One might add that this distinction is mainly relevant for close fields, whereas distant fields are likely to be independent of each other. There are certainly still other relevant characteristics of relations between fields, especially on the level of individuals participating in them simultaneously - the most discussed case in the current literature being certainly the problematic combination of family and occupational participation. Relations between fields are likely to play a major part in spill-over effects between individuals' partial (i.e., field-specific) trajectories. ${ }^{5}$

Persons' social integration conceptualised as participation profiles

Individuals who participate in a social field - as members of a family, as pupils in a school, as workers in a firm, as a politician of a constituency, as members of a club, as patients in a hospital, etc. - typically occupy a specific position in the field's internal organisation. In Bourdieu's terms, this position can be defined by the specific volume and composition of capital or assets they possess. In more general terms, positions are specified in terms of their hierarchical level and of their locus in the field's labour division. ${ }^{6}$ Moreover, they are associated with a more or less clearly defined set of expectations or social role, representing the cultural component of the position. This

\footnotetext{
${ }^{5}$ We use the term of trajectory for biographical movements within a field (vertical and horizontal mobility or entry-exit sequences) and the term of life course for the overall biographical process. The life course is seen as a bundle of trajectories.

${ }^{6}$ An older, largely forgotten term for the horizontal location in a field is situs (Sorokin, 1959 ; Samuel and Yuchtman-Yaar 1979).
} 
leaves us with three elements defining an individual's situation in a given field: participation, position, and role. 7

Each of the three elements has its own implications. To participate in a social field means to be inserted in the field's structure. This includes to be exposed to the tensions inherent in this structure, to be socially identified as a member of the field, to integrate and to respect at least to some extent the field's culture, its values and norms. This means that the field has the social-psychological characteristics and consequences of a reference group (Kemper 2011).

To occupy a given position in a field's hierarchy means to endorse the interests and conflicts related to it, for example conflicts of loyalty between hierarchically superior or inferior individuals or groups, interests in one's own upward mobility or avoidance of downward mobility, to benefit from one's position's social prestige, and to cash the rewards related to it. These interests, rewards, and tensions are typically different and unequal according to the position's hierarchical level.

To endorse the associated role with its possibly multiple segments means to exert the rights and duties attached to the position: to interact with the according role partners, to adapt to the role's requirements, to react to the role-partners' expectations, and to adopt the related vision of the field and its environment or to manage some distance to the role expectations.

Thus, participation in a field is a phenomenon very rich in implications (or « thick », to cite Geerz' term, 1973), depending also on the characteristics of the field itself and on their possible change.

\footnotetext{
${ }^{7}$ How does Bourdieu's notion of habitus relate to the notion of role as we use it here? Whereas role means for us in a very classical sense the set of social expectations related to a concrete position in a social field, habitus is more related to a person's social origin and biographical trajectory. Bourdieu insists on the habitus being embodied, which makes it a much more personalised feature than the notion of role. This is further highlighted by the fact that individuals who enact a social role may have some - varying - leeway of role interpretation on the basis of the distance to the role that they may uphold as individual actors. On the contrary, "habitus distance" appears as a contradictio in adiecto. We would hypothesise that a person's biographical sequence of enacted roles is one major source of the habitus she or he develops.
} 
So far, we have developed the three aspects related to membership in one social field.

However, participation in social fields is typically multiple, at least for adults in contemporary societies. Therefore, the overall social location of an individual is given not just by one position, role or participation. We must consider the whole configuration of participations (cum positions cum roles) the individual holds at a given moment of her/his life. For the sake of simplicity, let us call this configuration a participation profile, without forgetting the threefold meaning of each participation. ${ }^{8}$

\section{The life course as a sequence of participation profiles}

So far, we have conceptualised individuals' static location in the relevant social fields in which they participate at a given moment in their life. Since life is a process, we need to give this conceptualisation a dynamic turn. Participations, positions, and roles can change, and we can consider that life change in these terms is exactly what corresponds to the sociological perspective on life courses. Therefore, an individual's life course or movement through social space can be analysed as a sequence of participation profiles. Let us single out four features of this perspective:

First, participation in various social fields is a less studied aspect of people's societal integration than position but certainly no less important. The latter is regularly addressed by research on social stratification and mobility and routinely figures in many empirical analyses, even if they may not be cast in life-course terms.

Second, a multi-participation vision makes it possible to study the scope of an individual's participation profile. The scope of a participation profile is given by the number of participations (and with them also positions and roles) it comprises. A characteristic change of profile scope (according to an inversed U-curve) can be observed over the life span : for a new-born, life begins typically by participating in a

\footnotetext{
8 Multiple participations imply that everyday life is made up by " transitions » from one field to another. This is, of course, not the same meaning than that of life-course or membership transitions. Everyday transitions usually occur between participations that belong to a person's actual participation profile whereas membership transitions are part of the change of that profile.
} 
single field, his or her family of origin. While growing up, the number of participations increases and can become more or less considerable during adult life. Later, participation tends to decrease again with aging, often down to a single field of participation, for instance an institution for elderly persons. Little is known about the consequences of profile scope and its biographical change. Some indications suggest that there may be an optimal number of participations which is higher than one. Moen (1992) in her research about women's health has shown that occupying multiple roles is positively related to various aspects of health later in life. ${ }^{9}$ One may then ask what such an optimum and its under- or overrealisation by a person's actual participation profile means for the person. Is one happiest if there is an optimal fit between one's participation profile and one's personal "participation potential"? What is the role of social norms about what a participation profile socially considered as normal should be at a given moment of life (including gender-typical variations ${ }^{10}$ )? And what are the consequences of "deviance" with respect to such norms?

Third, it follows from our conception of the life-course that life-course transitions between fields are more consequential for persons' lives, social contacts, identities, and well-being than «mere » positional changes within fields. This is so because participational changes include moreover exits from occupied or entries into new social fields. In terms of dynamics of acquisition, conversion and transfer of capital we can hypothesise that positional changes within a specific field tend to correspond to slow and continuous accumulation processes, otherwise called intragenerational mobility. Changes from one field to another are often related to processes of conversion of one form of capital into another that may proceed more rapidly (Savage et al., 2005) and are likely to be more fundamental on the level of personal experience.

In our perspective, the much studied transition from school to work is a particularly important change of the participation profile. It corresponds simultaneously to a

\footnotetext{
${ }_{9}^{9}$ In social science research, optima are difficult to operationalise. Nevertheless, they have some theoretical plausibility and should not be discarded offhand. One forerunner on this topic is Bott (1957) with her hypothesis that each individual has a certain potential of sociability that may or may not be adequately sollicited by the person's pattern of relational integration.

10 See Krüger and Levy (2001) for a discussion of these variations.
} 
change of (dominant) participation and to a conversion of educational and cultural capital into economic capital (that includes in this case hierarchical position as well as income), with potentially far-reaching and long-lasting biographical effects. Participational changes often bring along changes in profile scope, because exits and entries may not balance each other but occur alone or even more or less simultaneously. In the light of our hypothesis, one can usefully think of critical life-course transitions as being of the participational and not just positional type (Levy et al. 2005, Liebig \& Levy 2015).

It goes without saying that any change of position, participation, or role is a fundamental part of individual, life-long development: as an instigator or as a result of individual/personal changes and action. It affects not only people's social location and interactional status, but also their personal outlooks, self-perception and well-being, spurring a host of learning and adaptation processes. As long as there are such changes in a person's life course, her or his personal development goes on.

Another, fourth feature of our theoretical proposition that we have already mentioned is that the basis for life-course analysis it offers does not primarily depend on chronological time or age (without excluding it), but on change in individuals' configurations of social (societal) integration. It neither depends on whether a given sequence of participation profiles is frequent or singular in a population. The degree to which specific sequences of participation profiles are generalised or related to age is an expression of their degree of standardisation and points to the contextual topic of life-course institutionalisation.

\section{Individual vs. standardised life courses}

In a life course perspective, participations in social fields can, but need not follow a specific successive order. Our conception of life courses as sequences of participation profiles can be used to analyse individual life courses, regardless of their degree of similarity or dissimilarity with others. Life courses may or may not follow fixed pat- 
terns. Even if life courses were completely individualised, they could still be ana-

lysed in those terms because they are as many movements through social space characterised by more or less multiple sequences of participations, positions, and roles. If there is some regularity in life courses, its source is likely to lie outside the life courses themselves (unless we conceive of them as fully "programmed" by individuals' adherence to cultural norms or biology - a view that clearly contradicts empirical evidence).

If the analytical vision of life courses presented up to this point does not automatically imply life-course standardisation, it proposes a rationale to study it. In line with studies of the United States' and Europe's historical demography (Imhof 1986), Kohli (1985) has elaborated a theoretically differentiated and empirically plausible thesis of historical life-course standardisation. His model distinguishes three dimensions along which such standardisation has taken place since the $18^{\text {th }}$ Century:

- Chronologisation: time plays an increasing role (in the form of ageing and of socially defined age groups) and replaces categorical or generational affiliations. Crucial events (transitions) are increasingly tied to individual age.

- Sequentialisation: biographical phases are increasingly ordered sequentially (for instance compulsory schooling during youth and preceding labour market entry, related to the prohibition of child labour).

- Biographisation : a strongly agentic vision of biographical achievement (in accordance with the American Dream) becomes more important: every individual is increasingly considered personally responsible of his or her successes and failures. ${ }^{11}$

The first two dimensions represent structural features of modern life-course changes, the third a cultural one. Kohli's historical portrait implies that two to three centuries ago, life courses in Western societies have been very little standardised, even with

\footnotetext{
${ }^{11}$ In the more recent, still lasting phase of life-course destandardisation, biographisation is likely to be pushed even further, but this time due to a more structural mechanism that diminishes the possibilities of biographical projection and planning ; one very concrete example is the disappearance of seniority as a criterion for upward mobility in public administrations. (We thank an anonymous reviewer for this idea)
} 
respect to age norms. This may be strongly, although not exclusively, related to the duration of life. As long as people may "normally" die at any age, starting with birth or even before, there can hardly be a normative age for death. With health and peace conditions improving in a given population, the probability to die before old age diminishes and a social "time for dying" - to cite Glaser \& Strauss' (1968) study of the institutional handling of scheduled and non-scheduled deaths - becomes factually possible and socially credible.

This long-term development has certainly interacted with industrialisation, but cannot be considered a simple consequence of it because historically it set in before. It can be seen as a corollary of bureaucratisation in the sense of Weber, with its specific logic of rationalisation. Especially the increasing reliance on age as an easy-to-handle criterion for public administration is an integral part of bureaucratisation (as for instance in the case of age-based definitions of who is to be considered a child for implementing the prohibition of child labour, introducing generalised compulsory schooling, and the establishment of various formal age thresholds for legal and civic majority or for retirement).

This development of increasing standardisation has most probably reached its peak in the middle of the $20^{\text {th }}$ Century, and has afterwards given way to inverse processes of destandardisation (Held 1986; Macmillan 2005; Widmer and Ritschard, 2009).

Given the historical contingency of the phenomenon of standardised life courses with age playing a major role due to its administrative use, we consider the relation between life courses and individuals' age not as a natural corollary but as socially constructed on both the structural and the cultural level of social organisation. It is historically variable and at least potentially negotiable for individual actors (even if so at some - maybe considerable - cost). We insist therefore on defining life courses as specific sequences of participation profiles, whatever kind and degree of age gradation might be involved. This also means that analysing life courses in terms of a postulated "age stratification", as Riley et al. (1972) proposed, does not seem analytically helpful, mainly for two reasons. First, to postulate a more or less autonomous age stratification would mean that age works as the central social good that is at stake in 
this kind of stratification, that age stratification has its own mechanisms of upward and downward mobility (although it may be hard to envisage downward age mobility if we are not referring to another, implicit criterion of stratification than age itself), and also mechanisms that legitimise age inequalities. Such an age stratification would have to coexist with the all-encompassing social stratification that principally structures contemporary societies. This seems implausible seen from a stratificationtheoretical perspective. Second, even though formulated in structural terms, this conceptual use of age tends to essentialise it, obfuscating its socially constructed and historically contingent significance. The alternative approach on the basis of the postulate that the age-gradedness of life courses in contemporary societies results from their historically specific institutionalisation in these societies allows us a much more open and, we think, more realistic analytical vision on the constitution, reproduction, and change of the relations between age and the factual form life courses take in a given period of a given society. ${ }^{12}$

As many authors have pointed out, individuals in modern societies tend first to participate in the field of education, then in the fields of family (of procreation) and employment and finally they leave the field of employment with retirement. Kohli strongly insists on the central role of paid work in the process of standardisation. He goes as far as to claim the emergence of a single, three-phase model of modern life courses mainly structured by the employment. This, however, would be an insufficient account of overall life course patterns in contemporary societies. At least for adult persons, life courses typically consist of several coexisting trajectories. According to our basic definition of the life course as a sequence of participation profiles, a model of a "linear" sequence of three exclusive participations in major societal fields is not plausible. It does not contain multiple participation, not even as the link be-

\footnotetext{
12 See Bernardi (1985) for a detailed study of age-graded or, as he calls them, age-class societies in the anthropological record. In these - mainly African - societies (e.g., the Dogon), there is no analytical " competition " between social stratification and age stratification as they are basically stratified in terms of age. But interestingly, in these cases, age is socially, i.e., collectively determined, and transitions do not occur at a certain chronological age of individuals, but at a moment where the elders of the society decide that a new promotion should be constituted. Anthropologists even report cases where young people having acquired more social experience and knowledge outside their society than their age peers were declared older, i.e., belonging to a higher age group, when they returned (Parin et al. 1963).
} 
tween partnership (or parenthood) and employment. Linked lives - a major factor in life-course gendering - cannot be conceptualised with Kohli's single three-phase model (as Kohli, 2003, later recognized himself).

Gendering is another important part of actual life-course standardisation (Levy and Widmer 2013). Gender-typed life courses of men and women remain to a variable, but in some countries large extent complementary to each other. Kohli's three-phase model describes only the male part of the two halves. That complementarity includes hierarchy because the male half is principally dedicated to gaining the couple's or family's living. The female half includes job interruptions and -reductions. Therefore, the income it can contribute and also the job chances it can accumulate give it a secondary status in the couple and renders the female part economically dependent. This inegalitarian effect, however, depends strongly on the availability of extrafamilial child care facilities. Thus, the linking of a male and a female life course by the family is a crucial basis of gendering, with important cross-national differences correlated with more general welfare-state profiles (Levy 2013, Esping-Andersen 1999).

\section{Life-course institutionalisation}

How does life-course standardisation come about? In descriptive terms, we can speak of standardised life courses when a majority of individual life courses show similar patterns. However, the concept of standardisation also hints at processes of social construction that produce the standardised trajectories we may find empirically. Besides ideological or cultural factors, it is highly likely that life-course standardisation arises from structural forms of institutionalisation (especially if these are also culturally legitimated). The reason why this phenomenon has only rarely been studied in a holistic life course perspective (but see, for instance, Han and Moen 1999, Heinz and Marshall 2003, Moen and Sweet 2004), is probably that no single specialised institution is specifically geared towards standardising life courses. Because 
many and very diverse institutions contribute to the standardisation of individual lives, the social visibility of their institutionalisation has remained limited.

Life-course institutionalisation is not only the result of combined strategies of a multitude of institutions, it also occurs rather indirectly than directly. This explains why the various institutional mechanisms impacting on life courses are rarely synchronised and may even be in conflict with each other. On the basis of empirical research, we distinguish five types of life-course relevant institutions that are often working in combination (Krüger 2001, Leisering 2003, Liebig et al. 2014) ${ }^{13}$.

Phasing institutions are those which individuals have to pass more or less compulsorily: education, paid work, and retirement (Mayer and Schoepflin, 1989; Fasang, 2010). They directly regulate people's participation profiles and bring them into a sequence. Thus, they define specific biographical phases of (pre-)dominant participation, bounded by an entry transition at the beginning and an exit transition at the end. These phases and moments can, but must not necessarily coincide with people's chronological age. By sequencing life courses and by regulating the ways and extent to which individuals can acquire life-course relevant resources and can use them in their biographical projects (often by capital conversion in Bourdieu's sense), phasing institutions have a particularly strong impact on life courses. Because they convey gendered resources, such as specialized qualifications that are gender-typed, they also directly contribute to institutionalise gender segregation. Even though the aspect of participation may seem to be primordial for phasing institutions, the positional aspect must not be neglected. Participation in phasing institutions implies also being subject to these institutions' rules and practices of promotion (upward or downward positional change) and of accreditation (concerning capital conversion from one field to another).

\footnotetext{
${ }^{13}$ Needless to add, that such processes of institutionalisation may concern any aspect of the life course as we define it. To the extent to which such institutionalisation is multiple and not coordinated, various aspects of life courses may be differentially and also incoherently institutionalised. What is more, life-course destandardisation is most likely to follow from either decreasing institutionalisation or from an increase in institutional incoherence with respect to life courses.
} 
Relating institutions link lives together, the most important in Western societies being the family. The family's function of life-linking does not only concern the adult partners of the couple but also parents and their children, as highlighted by the simple fact that the relevant phases in the family cycle are currently related to life transitions of the children (pre-school, school, post-school). ${ }^{14}$ Monogamy, heteronormativity and a more or less clearly gendered division of labour in the modern male-breadwinner family have been institutionalised since the $19^{\text {th }}$ century. This implies the well-known organised, "Parsonian" complementarity in the female and male partners' participation profiles: the female profile is largely concentrated on intrafamilial activities, the male one on extrafamilial activities, notably employment, but also politics and participation in other fields. This complementarity includes strong status dependence of the female on the male partner because the family's collective social status is principally based on paid extrafamilial work. ${ }^{15}$ Families seem a priori largely dominated and influenced by the behaviour of their adult members, which could suggest a high degree of autonomy. But their existence and internal organisation (gendered labour division) is strongly enforced by their institutional environment, leaving often little decisional leeway to the family's adult actors, whence its structuring importance on its members' participation profiles, life courses, and their gendering (Drobnič et al., 1999). We shall come back to the mechanisms that can link lives together.

Supporting institutions assist individuals to solve biographical problems resulting from their participation in more than one socially demanding field. They act on the acquisition and redistribution of certain resources or capitals and in this way influence the positions of individuals. Thereby, they act on positional or resource-related

\footnotetext{
${ }^{14}$ A recent empirical study by Widmer and Gauthier (2013) shows that in contemporary Switzerland, $54 \%$ of people's cohabitation trajectories correspond quite closely to Aldous' FLC model (Aldous 1996). Thus, this model still corresponds to a widespread social reality although its status is not at all "monopolistic".

${ }^{15}$ In contemporary society, the completely « complementary » model of heterosexual partnership has become rare, but modified forms continue to exist to varying degrees. To take these attenuated forms of the traditional model into account, Krüger and Levy (2001) have proposed the concept of gendered master statuses, this term meaning that one participation in men's and in women's profiles is dominant, other participations being allowed to develop only to the extent to which they do not interfere with the requirements of the dominant one. This is a specific way to take into account that not all participations (and the corresponding fields) are of equal importance for an actor.
} 
accumulation processes (or social mobility), but also on participation. Typical supporting institutions are public child-care and day schools which aim at helping parents to combine involvement in family and paid work. Research has shown that in different European welfare state regimes the transition to parenthood can take rather distinct directions: in the Scandinavian social-democratic regimes long and egalitarian parental leaves and a dense network of child-care institutions allow a majority of young couples to continue a gender-egalitarian life after the birth of their first child. In conservative and even more so in liberal regimes, where these supporting institutions are less available or altogether lacking and parental leave remains often strongly gendered, becoming parents leads to a re-traditionalisation of the couple ${ }^{16}$ and a differentiation of female and male trajectories according to the breadwinnerhomemaker family model (Bühlmann et al., 2010; Grunow et al., 2012). Hence, well developed supporting institutions have the potential to overcome traditional gender roles and unequal gender relations. On the contrary, restrictive rules of availability and specific, socially selective ways of functioning can contribute to reproduce gender inequalities.

A fourth type of life-course relevant institutions may be called normalising or repairing. These institutions enter into action when some kind of life-course turbulence or lifecourse accident occurs: the health system or unemployment services are examples of this type of institution. ${ }^{17}$ Normalising institutions work not only or not even primarily on social relations and individual capabilities and resources, but also on felt needs, identities, motivations, and more generally on individuals' reflexive functioning and subjectivity. By doing this, they frequently impose models of human agency that ap-

\footnotetext{
${ }^{16}$ By re-traditionalisation we mean the (mostly partial) return of the couple's social organisation, especially with respect to its internal labour division (who does what) towards the traditionally genderspecific model (male main or only breadwinner, female homemaker). This model, theorised by Parsons \& Bales (1955), has been very influential in family sociology until the beginning of the 1970ies, but its descriptive side has not lost all of its relevance.

17 With a view to completeness, we should mention in this context that total institutions such as prisons or psychiatric clinics have a relevance opposite to life-course normalisation as they interrupt «normal » life courses for the very reason of their total character, especially if participation in them takes on a longer duration. Therefore, they are not concerned by our typology (except for the family of origin which is part of the phasing institutions). Repairing institutions may typically intervene after a period passed in a total institution.
} 
pear as normatively narrowed if compared, e.g., to sociological models of agencywithin-structure (Archer 2000, Settersten and Gannon 2005). Recent political pressures on developed welfare states tend to mainstream the functioning of service institutions towards a life-course model we can call "marketisable" biography. Based on individualised autonomy and employability (Dahmen 2014), they conceive of individual actors as omni-competent managers of their life courses. Thus, they are streamlined with the general movement toward ever-increasing "biographisation" diagnosed by Kohli (1985).

These four types of institutional intervention contribute to direct life-course institutionalisation. Institutions of a fifth type may have indirect, mostly unintended - but nonetheless important - effects on life courses and their gendering. These may be called background institutions. Public and private services, shops, the health system, schools, public infrastructures such as transportation, are not geared to influence people's life choices and consequently their life courses. If the four types of direct institutionalisation are based on rather explicit and mostly normative models of human agency, background institutions operate on the basis of implicit assumptions of normality, including hegemonic assumptions about femininity and masculinity and about a more or less gender-biased family model. As these assumptions are embedded in these institutions' tacit functioning, they have the character of a self-fulfilling prophecy. They frame not so much the cultural than the structural environment of everyday life. Hence, their implicit assumptions about gender are guiding people's life courses as well as their everyday decisions. Persons who wish - or are forced - to live according to a social model incoherent with these institutional assumptions of normality find it very difficult to do so on a practical level. It can be difficult for instance to live as a single parent with a child, or by organizing family life in a nongendered way. As they don't fit into the institutionally presupposed model, they have to cope with problems of handling their everyday life that persons who are in line with that model usually don't have to meet. Examples for this can be difficulties to organise daily schedules in the midst of conflicting institutional rhythms or employers' expectations of unlimited occupational engagement by their male employees, whether or not they have children. 
Various forms of life-course institutionalisation concern both participation and position, and also the roles related to them; generally all three aspects will be affected by direct or indirect institutionalisation. From the point of view of direct institutionalisation, changing participation is a matter of entry into or exit from a phasing or relating institution (or the field it is structuring) whereas changing position is a matter of upward or downward movement within that field (more exactly, within one of the organisations it contains). Both types of movements are more or less strongly and directly administered by the field's decision-making bodies, especially within the phasing institutions (be it a school, a firm, a service attributing social allocations differently and maybe with less internal control in the case of a family). Background institutions exert their effects indirectly by imposing their procedures and rhythms of functioning.

With respect to the gendering of life courses, we can draw the conclusion that unlike many classical analyses of the social construction of gender can make believe, doing gender is as much an institutional achievement as an interindividual one (West and Zimmerman 1987). More generally, these insights should encourage us to analyse life courses within their meso- and macrosocial context, and this not so much as the passive, static theatre or arena in which they take place than as the major incentive structure that intervenes in their fashioning (Fligstein \& McAdams, 2012).

\section{Summing up}

Before engaging in a discussion of some more specific topics in life-course analysis in the perspective we are proposing, let us briefly restate our basic postulate and its implications. Our point of departure is that the life course should be sociologically addressed as a movement through social structure. From this postulate, at least four consequences for analysis follow directly: 
1. Life courses are principally identified by individuals' sequences of participation profiles and cannot, for instance, be approached as purely normative or narrative phenomena.

2. While age has certainly an intimate correlation with structurally defined profile sequences, it should not be seen as their defining ingredient. The strength of that correlation should rather be seen as a measure of age-based societal chronologisation, i.e., life-course institutionalisation. As a corollary, the notion of age stratification does not really make sense in contemporary societies because their stratification is neither based on age nor does age constitute an alternative system of stratification that would coexist with general social stratification.

3. Life courses can be sociologically analysed even if they are not standardised.

4. The life course is not just one more field of sociological study. It is a direct ingredient of the notion of a socially structured space inhabited by individual actors. Therefore, it is - at least potentially - part and parcel of any social-structural analysis.

\section{Principles of the life-course paradigm revisited}

After having exposed our conceptual sketch, we endeavour now to revisit Elder's five principles of the life course paradigm in order to see what our framework can bring to them. Elder has formulated his well-known five principles in slightly varying versions; we cite their formulation according to a chapter contributed to the Handbook of the Life Course (Elder, Kirkpatrick Johnson and Crosnoe 2003, an earlier version is, e.g., Elder 1995): life-span development, agency, time and place, timing, and linked lives. These are indeed crucial aspects that should systematically be taken into account whenever life courses are under study. As we stated at the beginning, we feel that these principles continue to be relevant, but should be complemented in order to build a systematic and explicit framework for life course analysis. 
From life-span development to life-course cumulation

The first of Elder's principles is that life must be viewed as a cumulative process, to be studied as a whole.18 Biographical experiences, their personal handling, assimilation, and consequences cumulate to form a person's life-long development, be it viewed through the lenses of an Eriksonian (Erikson 1982), Durkheimian (1968) or Schützian (Schütz \& Luckmann 1973) conception. Biographical cumulation or sedimentation is not necessarily but can be unilinear. This is especially so if it concerns aspects of social stratification or inequalities. The CDA or cumulative dis-/advantage hypothesis (e.g., Dannefer 2003) is a concrete form of the unilinear variant of cumulation. It postulates that advantages or disadvantages cumulate over the whole life, but potentially includes also phases of compensation and reduction of advantages.

Advantages and disadvantages do not occur randomly during a life-time, but according to a logic of path-dependence that usually starts with early advantages or disadvantages, brought about by people's social origins. These early (dis-)advantages condition later ones that tend to have the same direction, maybe even despite attempts at compensation (see Dannefer 2003, 2009; DiPrete \& Eirich, 2006; Pallas \& Jennings, 2009). This hypothesis is well-known as what Merton earlier $(1968,1988)$ called the Matthew effect in social inequalities, ${ }^{19}$ focusing the specific field of science with scientific reputation as its central stake. A similar idea of accumulation is at the basis of Bourdieu's concept of capital (1986; see also: Savage et al., 2005). Positive or negative biographical cumulation can concern experiences, attainments or failures, "acquired"

\footnotetext{
18 This formulation remains sociological and does not pretend to fully include the social-psychological or developmental-psychological point of view. Therefore we cannot integrate these approaches here, even though it would be a welcome complement because it would make easier connexions to biological aspects that we do not include either - think, for example, of Baltes' SOC model (for Selection, Optimisation, and Compensation, see Baltes 1987). For a fuller discussion of the relationship between life-course sociology and life-span psychology see Settersten (2009).

${ }_{19}$ Reference to the well-known passage in St. Matthew's gospel describing the experience that the rich get richer and the poor poorer, "For unto every one that hath shall be given, and he shall have abundance: but from him that hath not shall be taken even that which he hath. » (Matthew 25 :29, King James Version).
} 
social labels, ${ }^{20}$ and notably also resource or capital accumulation (Elman \& O'Rand 2004), e.g., biographically growing differences in education, in wages, or in health, crystallising into socially positive (ascending) or negative (descending) careers. Biographical processes of accumulation and acquisition differ with respect to specific forms of capital. Different forms of capital have different degrees of convertibility and transferability (Savage et al., 2005), which is part of the relationships between the social fields they belong to. Whereas economic capital can buy many things within the economic field, it is, for instance, not completely transferable into the family field (although it is certainly one of the important bases of intrafamilial power, as many studies have shown since Blood \& Wolfe 1960). Similarly, cultural capital, specifically in its embodied form, cannot be bought, i.e., it is not accessible to the conversion of economic capital.

Seen on the background of our theoretical framework, the hypothesis of cumulative dis-advantages (CDA) as it is mostly discussed in the literature refers to positional rather than to participational changes. But this is not exclusively the case : women's often interrupted trajectories in paid work are a telling case in point for the relevance of biographical cumulation for participation as well: the longer an employment interruption (suspended participation), the more difficult it makes job re-entry and the more likely such re-entry, if it happens nevertheless, will include downward mobility (i.e., position). Accumulation is often tantamount to upward or downward social mobility, regardless of the field we consider. It concerns material as well as immaterial resources, such as formal education. An important example of an administrated accumulation of an immaterial good consists in the fact that most firms' encouragement policies in matters of continuing education are used to reward well-performing or higher-level employees rather than to give a compensatory push to the lower ranks. Accumulation concerns also more psychological resources like cognitive complexity and flexibility and the resulting self-directedness (Kohn \& Schooler 1978, Rodin et al. 1990), or beliefs of personal control or self-efficacy. Besides participa-

\footnotetext{
${ }^{20}$ Note in passing that the recent notion of scarring with its double meaning of external labelling and internal suffering (e.g., Strandh et al. 2014) is yet another reference to the basic mechanism of accumulation during the life course.
} 
tional life-course changes, mechanisms of biographical accumulation (positional changes) are thus also important. They are efficient both on the level of individual experience and on the macroscopic level of social mobility or of the reproduction of overall social inequalities (Bourdieu 1979).

In consequence, poverty, an eminently positional aspect of people's social location, should be treated in a life-course perspective under the double point of view of social origin and success vs. failure of own capital acquisition. The comparison between position of origin, own initial position, and own position attained at a given moment in one's life course is classically but insufficiently treated under the headings of interand intragenerational mobility, including sequences of entry into and exit from poverty. This point of view is, however, insufficient because it narrows down excessively the mobility problem to a strictly positional aspect instead of including more qualitative or "horizontal" aspects, for instance of qualifications that may encounter the problem of skill mismatch. This can be a case of hierarchically high-ranking, but qualitatively obsolete cultural capital that may lead to downward mobility or even to loss of employment.

\section{Life-course location in time and place}

Elder's second principle states that life courses are located historically as well as spatially, i.e., in time and place. Historically and territorially inscribed institutions play a major role in the shaping of life courses (Elder, 1974). Once one is aware of the various forms of life-course institutionalisation, it is only a matter of consequence to also consider that life courses occur in historically specific periods and in varying territories and countries, more exactly in locations characterised by varying institutional outfits. Institutional change and stability play obviously an important role for the social conditions, opportunities and constraints under which life courses unfold.

Location in historical time: Societies, especially their institutional framework, usually (but not always) change slowly. Thinking of Mannheim's (1928) analysis of genera- 
tional situations and relations, one may hypothesise that generations, i.e., cohorts that share a common historical experience, come to exist only in times of rather rapid change such as during a war or an economic boom period. One of the rare contemporary instances of radical institutional change on the societal level that can illustrate the importance - and also its uncommonness in contemporary societies - of this historical aspect is the post-communist transition in Eastern-European countries. By hypothesis, distinguishing three subsequent cohorts, we can postulate that the older population cohort has completed its professional trajectories still under the relatively gender-egalitarian full-employment regime of the soviet period and is often stabilised in retirement, be it only by tiny remainders of pension. The middle-aged cohort is likely to have made a safe education-to-work transition still under the socialist regime, mostly also its biographical transition to partnership, marriage, and parenthood, but has mostly had its adult occupational trajectory shattered or at least disturbed by the politico-economic transition Many members of this intermediate cohort will have seen their acquired qualifications depreciated with resulting downward job mobility even if they could maintain their employment, all this often ending in unemployment and economic dependence on their parents, pushing both cohorts towards poverty. The younger cohorts, born during or after the transition, have never experienced the standardised biographical model that formerly prevailed. They have to cope from the outset with the uncertainties of weak post-socialist welfare states that can hardly dampen the negative employment effects of their ailing economies and leave them durably vulnerable, often doing at best some form of informal or otherwise precarious work (Mayer 2001; Aidukaite 2009; Diewald, Goedicke \& Mayer, 2006). This illustration highlights the importance of the institutional environment of life courses and its historical change. Given this importance, we are tempted to postulate that (historical) "time" can be conceptually recast to a large extent as the (historical) development of life-course relevant institutions.

Location in socially structured space: Social structures are generally spatialized. Therefore, life courses cannot be adequately understood without taking into consideration where they occur, « where » meaning, of course, not so much the strictly geographical than the social and especially the institutional aspects of place. Whereas organisa- 
tions, especially firms, may be highly mobile in geographical terms (especially under conditions of globalisation), polities, administrations, public services and infrastructures are typically tied to a fixed territory and cannot migrate. As they are an important part of the opportunity structures that constitute people's everyday environments, this fact highlights the social importance of place in general as well as in relation to life courses more specifically. ${ }^{21}$

Changing spatial location - migration: International differences, especially between richer and poorer countries, are one of the main forces that stimulate international migration - another central, still too rarely explored topic for life-course research. On the individual level, migration typically combines participational and positional changes that may be particularly difficult to handle for the migrants (Palloni et al., 2001). The "crossing" of dimensions of structural differentiation and related migratory movements may be illustrated by imagining the emigration of a well-educated person from a poor African country to Europe - an expedition that has become increasingly dangerous if undertaken illegally, as tens or even hundreds of thousands try each year. Potentially, such a person occupies an intermediate or even high social position in his/her country of origin, but may find it difficult to get hired into a position corresponding to her/his qualifications. Let us assume that this attempt to change one's context of participation succeeds and that the migrant finds a job in the country of immigration. The status conferred by country membership (participational change, not to be confused with citizenship or civic status ${ }^{22}$ ) seems clearly higher than that of the country of emigration. But very likely, this upward mobility with respect to international position is counterbalanced by the fact that the immigrant's civic status (foreigner, maybe with a precarious or even illegal situation)

\footnotetext{
${ }^{21}$ Of course, the relation between social systems and the territory they occupy or use is more intricate than the mere spatial location of social structures. It should be analysed in terms of specific exchangeand also dominance relations between a society and its natural environment that have become heavily unilateral as social ecology shows (Bruckmeier 2013): we can speak of outright exploitation and domination of nature by present-day societies. This particularly fascinating line of thought goes beyond the objectives of the present article.

22 We denote by civic status a specific positional dimension related to participation in a national context and stretching from illegal presence (and therefore great social vulnerability) to full citizenship, with various intermediate positions depending largely on national and maybe also provincial legislation and attribution practices.
} 
within the country of immigration is much lower than it was in the country of emi-

\footnotetext{
${ }^{23}$ Ostensibly, this question is often highly loaded with ideological commitments, as seems for instance to be strongly the case for the only example we wish to cite, i.e., the debate provoked by Hakim's socalled preference theory (Hakim 1998, Crompton and Harris 1998a, 1998b). Its main stance boils down to the postulate that women consciously choose their pattern of family- vs. employment engagement (and consequently their life-course pattern with respect to these to fields of particpation) instead of being structurally induced into it. Another problem is the polysemy of the term - Marshall (2010) identifies no less than eight different meanings of "agency". Somewhat disrespectfully, we would rather like to suggest that it may be just another version of the hen-and-egg problem of what comes first. If discussed on the level of general principles, so-to-say the principle of the hen and the principle of the egg, the problem has no solution; if discussed on the concrete level of a specific egg and a specific hen, there is no problem. In other words: there is hardly ever a one-sided situation because human behaviour takes place typically within a specific opportunity structure that offers options and opposes constraints to individual actors, especially when they are projecting and constructing their life course. We therefore associate with Settersten and Gannon's (2005) heuristic formula of agencywithin-structure.
} 
debate. This implies to consider both agency and structural or cultural determination

With respect to life courses, agency is interesting in several respects. On the cultural level, the interpretive principle of agency has been strongly propagated as a pattern of social interpretation by Kohli's (1985) third aspect of standardisation that he calls biographisation, i.e., the individual attribution (or internal attribution, to use a socialpsychological term) of responsibility for the course of one's life. In some sense, the idea that life courses result from individuals' personal agency has become a popular ingredient of the individualist, largely structure-blind postmodern world-view. ${ }^{25}$ The problem with this interpretive schema, if generalised, is that it marginalises social influences, delegitimising by that token more sociological perspectives.

On the level of actual behaviour, we must distinguish between wilful, agentic influence on one's own life course and the life course being shaped by field-related and institutional influences. Let us cite one example that tends to accredit the idea that institutional influences are stronger than individual projects and tend to fix the limits within which agency may be realised. Le Goff and Levy (2016) report a three-wave panel study that asked couples during pregnancy, shortly after the birth of their first child and a year later about their intentions concerning an egalitarian or gendered attribution of family tasks and also about their practice. The study shows that most of the couples lived in a consistently egalitarian situation before they became parents, but moved after childbirth to an inconsistent one, still maintaining egalitarian intentions whereas their practice that had become traditionally gendered with the woman having reduced or even stopped her paid work and having taken up the bulk of unpaid family work. In the third wave the couples converged toward a new coherence, continuing their gendered practice but now with intentions modified towards this new factual traditionalism. This evolution of young couples during their transition to

\footnotetext{
${ }^{24}$ As agency designates individuals' capacity to act on their situation despite pressures pushing toward another outcome, we should also bear in mind its opposite, vulnerability, definable as "lack of resources or social weakness" (Hanappi, Bernardi and Spini 2015).

${ }^{25} \mathrm{We}$ do, however, not want to imply that Kohli, as mentioned in this paragraph, takes himself a postmodernist position. This is clearly not the case as he consistently looks for societal factors influencing life courses, agency, and their representations.
} 
parenthood reveals a process of familial re-traditionalisation that happens despite partners' normative convictions. These convictions do not suffice to maintain a practice that corresponds to them - a strong hint at extrafamilial factors that can explain the change on both the behavioural and normative level, as they seem to overrun these new parents' agency. If this interpretation is correct, it implies, of course, that the pattern thus observed will strongly depend on the institutional setup of the society considered, as research comparing various types of welfare states confirms (Bühlmann et al. 2010). These considerations illustrate a more general relationship between the individual and the societal level, making it virtually impossible to discuss agency without considering individuals' institutional environment and the opportunity structure it represents for them.

We have already pointed to a positional aspect of biographical agency that is sociologically trivial but practically no less important: agency depends to a large extent on the resources a person or a group can wield. These resources depend largely, if not exclusively, on their social position. More specifically, in contemporary societies, largely based on a commodified economy, purchasing power and hence for most people their income is structurally set as the most important single determinant of agency. However, as we stated earlier, income is not easily convertible into the specific capitals of all relevant social fields and therefore does not constitute the only socially relevant resource or type of capital. Therefore, lower ranks of social stratification are much more threatened to become vulnerable, resilience is easier to realise on the higher ranks. This consideration underlines the importance of integrating the perspectives of the life-course and of social stratification with a view to understand the empirical varieties of agency.

\section{Life-course timing}

Fourthly, Elder states that life courses, as any other processes, are a priori inscribed in chronological time. However, time is not enough to grasp them. The same holds for individual age, an individualised avatar of time: life courses unfold as persons 
grow older, but the simple term of ageing would be unfit to reveal what happens during a life course. The relation of life-courses to timing schedules is socially constructed to a large extent, and institutions play an important role in this construction (Neugarten et al., 1965; Settersten, 2003).26 Let us then primarily look at several ways life-course timing can be standardised, and how individuals handle difficulties with this dynamic.

Within the theoretical framework we propose, we can easily appreciate that life courses are organised by transitions (events) and periods between them that can be described as different participation profiles, their sequential ordering and durations. Furthermore, as Kohli (1985) has usefully reminded us, the tie between life-course events and chronological age is anything but intrinsic. Its social construction is especially favoured by bureaucratisation and can strongly vary in history. Especially, any bureaucratic administration can be supposed to prefer easy-to-handle age thresholds to considerations about the specific situation of individual cases, thus strongly contributing to life-course standardisation on the basis of age. This has an immediately "operational" consequence on the use of age as a proxy for life course: one can expect that life-course related variations by age are telling only in periods with a strongly enforced chronologisation of major biographical events (such as marriage or childbirth), whereas they are obscured when chronologisation is low. In other words, with chronologisation diminishing, analyses and visualisations of aspects of life courses in terms of age are likely to obscure regularities that are directly related to the lifecourse but not to age. This also means that under conditions of decreasing chronologisation, we have to expect an increasing divergence between individual actors' perception of the timing of their life courses (that will likely remain strong because life is anyway developing in subjective time) and the corresponding statistical patterns (that will become increasingly diffuse).

\footnotetext{
${ }^{26}$ Lest we would uphold the naively functionalist view that contemporary societies have found the perfect fit between the social treatment of different ages and these ages' intrinsic changes. The highly variable treatment of age and life courses in different cultures and in different historical periods of contemporary societies give ample evidence against such a view.
} 
It may be useful to stress that the correspondence of actual life courses to life-course norms, especially norms about timing and sequencing as studied since the work of Neugarten et al. (1965), does not only result from norm-conforming action, but reflects also direct institutional influence (Brückner and Mayer 2005). People may very well not act to conform to life-course norms but respect them nevertheless because of parallel institutional constraints that they do not have the resources (or effective agency) to avoid. A patent case of this situation is the difficulty of many parents to combine their family and occupational engagement in the absence not only of supporting institutions, but also of sufficient parental leave, and also of employers' acceptance to reduce their working hours (which is often strongly sex-specific). This is a case of imposed non-cumulation of participation in major fields of social action largely independent of explicit norms about the modelling of life courses.

A corollary of cultural and structural chronologisation and hence standardisation of biographical transitions and life courses more generally, is the deviant status of nonnormative sequences and participation profiles. The very standardisation of life courses can be reason enough for negative consequences of "wrong", out-of-schedule events. These events include those which interrupt or prevent "normal" processes of accumulation. Life-long learning for instance is not systematically integrated in procedures of admission, teaching schedules, or assessment criteria. Where educational institutions are largely built on the assumption that the major part of a person's education has to take place during youth and before entering the labour market, deviance from the timing that corresponds to this institutional assumption of "normality" may bear a much heavier penalty than deviance from "merely" cultural age- or sequence norms. An example for the latter situation is, for instance, the case of teenage mothers studied by Furstenberg (2007). These girls are clearly out of sync with their age groups' normative life-course timing, but the degree of resilience (or agency) they show indicates that the mere fact of a biographical event being out of schedule does not suffice to provoke negative outcomes. The absence of systematic institutional pressure may be one of the main factors that favour their resilience. 
Let us add another interesting finding that points to the fact that respecting normative expectations about timing or sequencing should also be seen as an achievement that needs a real investment of personal resources - resources that some persons' life courses do not allow to accumulate sufficiently. In a pioneering study with three different groups of psychiatric patients, Müller et al. (2013) found that patients living through standard trajectories, i.e., trajectories resembling those of non-patients, rather than trajectories that do not respect major transition and sequencing norms (e.g., by returns to normatively "earlier" participation profiles like living with one's parents after a phase of living autonomously), have a consistently higher level of mental troubles (such as somatisation, anxiety, hostility, or paranoia) than those living in a psychiatric institution or switching irregularly in and out of participations that are clearly ordered in the general population's trajectories. This finding makes such institutions appear as shelters for vulnerable, under-resourced persons against the oppressive potential of standard, highly biographised life courses in contemporary society. It leads to a further question for research at the intersection of sociology, social psychology and developmental psychology: what are the personal and social competences and resources that constitute people's ability to follow standard life courses, and what are the factors that favour or prevent their development?

\section{Life-course linking}

The principle of linked lives has been mainly studied in the case of partners living together, or parents and their offspring, as done already in Elder's Children of the Great Depression (Elder, 1974). Our framework of participation profiles seen in their institutional context leads us to look both for analytical depth and illustrative expansion about the linking topic.

First, what is the nature of the link between lives, i.e., between different persons' life courses? A helpful distinction may be the one between factors internal or external to the interpersonal relation at stake. Let us first cite what is perhaps the major example of internal forces of cohesion. In a structure-oriented perspective, the complementarity 
of partners' participation profiles in traditional husband-provider families, but to a lesser extent also in what may be called partially modernised family structures, is a specific (gendered) form of labour division (Levy, Widmer, and Kellerhals, 2002; Drobnič et al., 1999). This brings to mind Durkheim's argument according to which "organic", i.e., structure-induced solidarity on the basis of labour division or functional specialisation is a more effective factor of cohesion (i.e., linking) than "mechanical" solidarity, based on sameness or ideological consent. Therefore we can assume that the highly gendered labour division in traditional or neo-traditional couples constitutes the strong link that relates the partners' life courses to each other. Gendering of family tasks makes the alternative option of living separately highly fictitious because of the partners' structurally induced mutual dependence. ${ }^{27}$ Second, there are also external, i.e., extrafamilial forces relating the partners' lives, especially once they have become parents. These forces correspond mainly to the background institutions we mentioned above. To the extent that these institutions function on the basis of gendered normality assumptions, they contribute to the linking of partners' gendered life courses by something we could call structural induction.

Second, the concept of life-linking institutions with the family as its major instance, as developed earlier in this article, has hardly been developed on a more generally institutional level up to now (but see Moen 2003). It can help enlarge the analytical focus on that topic, although we can only ask some heuristic questions. Are there other instances of linked lives than those of cohabiting partners that may hint at other linking mechanisms? The case that comes most easily to mind is the relation of children and their parents (e.g., Elder, 1974; Fischer 1986), but also that of children and grand-parents. Other forms may be more distant and qualitatively more different - to what extent can, for instance, belonging to the same friendship network constitute a life-linking mechanism? Are there still other non-familial cases of linked lives, maybe economic partnerships in small firms or shared ownership of some im-

\footnotetext{
${ }^{27}$ Starting from this assessment, we may ask whether in less unequal couples, with a weaker link due to complementary labour division, the relation to the child or children constitutes an alternative linking mechanism, at least for the period of « active parenthood ». This should, for instance, show up in changing divorce patterns by age, i.e., by a trend towards « post-parental » divorce, after longer durations of marriage, as is actually the case.
} 
portant asset? Kinship relations beyond the immediate family circle? What about the link constituted by a common membership to a social class or a social category, or a minority community? Besides very special situations, these cases seem less likely to correspond to the idea of linked lives, but would merit to be examined under this aspect. Their comparison hints at the intensity or inevitability of the relation concerned as probably a major variable in its life-linking potential.

What are the essential ingredients of linked lives in terms of participation profiles? Is it the fact that one of the linked partners changes her/his participation profile if the other does? Can we construct a typology of interbiographical links based on their "nature" or quality (see Hagestad 2003)? Some interbiographically induced participational, status and role changes are so-to-speak automatic. For instance those related to the extant kinship order: one becomes a grand-parent as soon as a grandchild is born, whatever the concrete interpretation one gives to that status; one loses the status and role of spouse at the death of one's partner. Role changes can also have interbiographical effects, for instance the role of children and their relation to their parents is bound to change with the latters' growing longevity28. Being located in a system of complementary labour division, as discussed above in the case of couples, is another kind of link. Still another type of link could be based on having to share important constraints or resources, as in the case of shared economic property.

In order to have life-linking force, does an interpersonal relationship have to correspond to a strong tie, in the sense of Granovetter's (1973) distinction between strong and weak ties? We could argue that we speak of linked lives if there are important interdependencies and not just interpersonal relations that may remain temporary and non-obliging. A similar argument would be that as long as there are no welfarestate institutions establishing reliable forms of solidarity outside of kinship or communitarian networks of exchange, the latter are likely to remain strong enough to constitute binding interbiographical links. According to the crowding-out hypothesis,

\footnotetext{
${ }_{28}$ With Mead (1970) one can say that in contemporary and highly developed societies, these relations pass rather rapidly from postfigurative through cofigurative to prefigurative, a development that strongly undermines the legitimacy of the traditional, age-based generational hierarchy.
} 
these links should tend to disappear if such welfare-state institutions are working well (but see van Oorschot 2005). If this holds true, is the nuclear family the only lifelinking institution that remains effective (between adult partners as well as between children and their parents) once universalistic structures of solidarity have been institutionalised? Or is the family weakened by this meso-structural development as well? And will parental and particularly family ties become more important again if existing forms of welfare-state solidarity are reduced?

The possible examples we have mentioned show a rather wide range of variation in intensity or strength of links between lives that has not yet been theorised. How does life-linking come about more generally? Does its strength depend on its institutional backing, and how does this work? What can we say about life-linking mechanisms more generally, beyond the fact that ostensibly, they are not only interpersonal and situationally negotiable, but also institutional and more enduring?

\section{Conclusion}

This contribution sketches a sociological framework of the life course that is more structural than usual, often somewhat individualistic approaches. It goes beyond a list of heuristic or sensitising principles, is applicable to a wide range of empirical topics and situations, and allows us to integrate a large number of more punctual concepts and hypotheses as our discussion has tried to show.

Two complementary aspects are at the core of our conceptualisation. First, in its centre is a definition of the life course as a movement through social space, formulated more analytically as a sequence of profiles of the social location of individual actors. These profiles consist of actors' participations in social fields, each participation including also the position occupied in the fields' structure and the role held in this position. Life-course events can then be conceptualised as changes in the type and scope of participation, accumulative (positive or negative) changes in positions, and changes in the related roles. This structure-oriented approach integrates life courses 
into a general idea of a society's specific structure and the fact that it is "inhabited" by individual actors.

Second, beyond individual events and decisions of the life-course passenger and her/his immediate social environment, these sequences of participation profiles can be created, shaped and standardised by four main types of direct institutional interventions (phasing, relating, supporting and repairing institutions) as well as by indirect interventions by background institutions. Thus, life-course analysis is directly related to the institutional, meso-social setup that structures the social space of a societal unit.

In the light of this theoretical sketch, we revisited and discussed Elder's five principles, trying to anchor these principles in a more explicit and encompassing account of the social structure and of individuals' biographical travels through it. Life-course cumulation can, for instance, be understood as the slow accumulation of capital and the individual's consequential positional change within a field, but also as cross-field conversions of available capital. Or the concept of linked lives - sometimes criticised as trivial and shallow - can be enriched, as we can for example show how configurations of participation profiles within a couple or a family have certain social functions and evolve in typical patterns over the course of a biography, often triggered or pushed by extrafamilial factors. Related to the social-structural makeup of society, Elder's principles, which have hardly been clearly related to notions of social hierarchy or social differentiation, can be linked together in a more systematic way when related to the larger social structure.

To sum up, our structural framework of the life course helps overcome the theoretical individualism that implicitly or explicitly inspires many biographical analyses. At the same time, we think that the conceptual approach we propose remains sufficiently general and open so that it can be applied to a wide variety of topics and be connected to a vast array of theories. We even hope that it stimulates application of a life course approach to issues which have so far rather been neglected by life course research: international migration for instance, the interaction between different institutional interventions and their effects on the life course, or trajectories of poverty, 
vulnerability and resilience. Such a more interrelated and systematic theoretical approach of the life course might help us to realise more fully one of the "unfulfilled" promises of life-course research: to understand the functioning of social structures through the study of the individuals who move through them.

\section{Bibliography}

Aidukaite, J. 2009. Old welfare state theories and new welfare regimes in Eastern Europe: Challenges and implications. Communist and Post-Communist Studies 42(1): 23-39.

Alwin, D. F. (2012). Integrating Varieties of Life Course Concepts. Journal of Gerontology Series B: Psychological Sciences and Social Sciences 67B(2), 206-220.

Archer, M. (2000). Being Human: The Problem of Agency. Cambridge University Press, Cambridge and New York.

Atkinson, W. (2014). A sketch of 'family' as a field: from realized category to space of struggle. Acta Sociologica, 57(3), 223-235.

Baltes, P. (1987). Theoretical porpositions of life-span developmental psychology: On the dynamics between growth and decline. Developmental Psychology 23, 611-626.

Blood, R. O. \& Wolfe, D. M. (1960). Husbands and Wives. The Dynamics of Married Living. Free Press, New York.

Bott, E. (1957). Family and Social Network. Roles, Norms and External Relationship in Ordinary Urban Families. Tavistock, London

Bourdieu, P. (1979). The Inheritors. University of Chicago Press, Chicago (French original: Les héritiers: les étudiants et la culture. Minuit, Paris 1964). 
Bourdieu, P. (1975). The Specificity of the Scientific Field and the Social Conditions of the Progress of Reason. Social Science Information 14(6): 19-47.

Bourdieu, P. (1986). The forms of capital. In: J. G. Richardson (ed.), Handbook of Theory and Research for the Sociology of Education. New York: Greenwood, pp. 241-258.

Bourdieu, P. (1993). Some properties of Fields. In: Sociology in question (Vol. 18). Sage.

Bronfenbrenner, U. (1979). The Ecology of Human Development. Harvard University Press, Cambridge.

Bruckmeier, K. (2013). Natural Resource Use and Global Change: New Interdisciplinary Perspectives in Social Ecology. Palgrave Macmillan, New York.

Brückner, H., \& Mayer, K.-U. (2005). De-Standardization of the Life Course: What It Might Mean, and if It Means Anything, Whether it Actually Took Place. in: Ross Macmillan (ed.), The Structure of the Life Course: Standardized? Individualized? Differentiated? Advances in Life Course Research 9, 27.54.

Bühlmann, F., Elcheroth, G., and Tettamanti, M. (2010). The Division of Labour Among European Couples: The Effects of Life Course and Welfare Policy on Value-Practice Configurations. European Sociological Review 16(1), 49-66.

Crompton, R., and Harris, F. (1998a). Explaining Women's Employment Patterns: 'Orientations to Work' Revisited. British Journal of Sociology 49(1), 118-136.

Crompton, R., and Harris, F. (1998b). A Reply to Hakim. British Journal of Sociology 49(1), 144-149.

Dahmen, S. (2014). The Capability Approach and Sociological Conceptions of Agency: An Empirical Assessment on the Basis of an Analysis of Activation Policies. Social Work \& Society 12(2), http://www.socwork.net/sws/article/view/404 (retrieved on August 27th, 2015). 
Dannefer, D. (2003). Cumulative advantage/disadvantage and the life course: Crossfertilizing age and social science theory. The Journals of Gerontology Series B: Psychological Sciences and Social Sciences, 58(6), S327-S337.

Dannefer, D. (2009). Stability, Homogeneity, Agency: Cumulative Dis-Advantage and Problems of Theory. Swiss Journal of Sociology 35(2): 193-210.

Diewald, M., Goedicke, A., and Mayer, K. U. (eds.), After the Fall of the Wall. East German Life Courses in Transition. Stanford: Stanford University Press.

DiPrete T. A., and Eirich, G. M. (2006). Cumulative advantage as a mechanism for inequality: A review of theoretical and empirical developments. Annual Review of Sociology, 32, 271-297.

Drobnič, S., Blossfeld, H. P., \& Rohwer, G. (1999). Dynamics of women's employment patterns over the family life course: A comparison of the United States and Germany. Journal of Marriage and the Family, 133-146.

Durkheim, Emile. (1968 [1922]). Education et sociologie. Presses universitaires de France, Paris.

Elder, G. H. (1974). Children of the Great Depression: Social change in life experience. University of Chicago Press, Chicago.

Elder, G. H. (1995). The Life Course Paradigm: Social Change and Individual Development. in: P. Moen, G. H. Elder \& K. Lüscher (eds.), Examining Lives in Context: Perspectives on the Ecology of Human Development. APA Press, Washington, 101139.

Elder, G. H., Kirkpatrick Johnson, M., and Crosnoe, R. (2003). The Emergence and Development of Life Course Theory. in: J. T. Mortimer \& M. J. Shanahan (eds.), Handbook of the Life Course. Plenum, New York, 3-19. 
Elman, C., and O'Rand, A. (2004). The Race Is to the Swift: Socioeconomic Origins, Adult Education, and Wage Attainment. American Journal of Sociology 110(1): 123-160.

Erikson, Erik Homburger. (1988). The Life Cycle Completed: A Review. Norton, New York.

Fasang, A. E. (2010). Retirement: Institutional pathways and individual trajectories in Britain and Germany. Sociological Research Online, 15(2).

Fischer, L. R. (1986). Linked Lives: Adult Daughters and Their Mothers. Harper \& Row, New York.

Fligstein, N., and McAdam D. (2012). A Theory of Fields. Oxford University Press, New York.

Furstenberg, F. F. (2007). Destinies of the Disadvantaged: The Politics of Teen Childbearing. Russell Sage, New York.

Geertz, C. (1973). Thick Description : Toward an Interpretive Theory of Culture. in : C. Geertz, The Interpretation of Cultures. Selected Essays. Basic Books, New York.

Giele, J. Z., \& Elder, G. H. (eds., 1998). Methods of Life Course Research: Qualitative and Quantitative Approaches. Sage, Thousand Oaks/London.

Goffman, E. (1961). Asylums: Essays on the Social Situation of Mental Patients and Other Inmates. Anchor Books, Garden City.

Granovetter, M. (1973). The Strength of Weak Ties. American Journal of Sociology 78(6), 1360-1380.

Grunow, D., Schulz, F., \& Blossfeld, H. P. (2012). What determines change in the division of housework over the course of marriage? International Sociology, 27(3), 289-307. 
Hagestad, G. O. (2003). Interdependent Lives and Relationships in Changing Times: A Life-Course View of Families and Aging. in : Richard A. Settersten (ed.), Invitation to the Life Course. Toward New Understanding of Later Life. Baywood Publ., Amityville/New York, 135-159.

Hakim, C. (1998). Developing a Sociology for the Twenty-First Century: Preference Theory. British Journal of Sociology 49(1), 137-143.

Han S.-K., \& Moen, P. (1999). Clocking Out: Temporal Patterning of Retirement. American Journal of Sociology 105(1), 191-236.

Hanappi, D., Bernardi, L., \& Spini, D. (2015). Vulnerability as a heuristic concept for interdisciplinary research: assessing the thematic and methodological structure of empirical life course studies. Longitudinal and Life Course Studies 6(1), 59-87.

Heinz, W. R., \& Marshall, V. W. (eds., 2003). Social Dynamics of the Life Course: Transitions, Institutions, and Interrelations. Aldine de Gruyter, New York.

Heintz, B., \& Greve, J. (2005). Die "Entdeckung" der Weltgesellschaft. Enstehung und Grenzen der Weltgesellschaftstheorie. in: Bettina Heintz, Richard Münch \& Hartmann Tyrell (Hrsg.), Weltgesellschaft - Theoretische Zugänge und empirische Problemlagen. Zeitschrift für Soziologie (Sonderheft), 89-119.

Heinz, W. R., Huinink, J., \& Weymann, A. (eds.). (2009). The life course reader: individuals and societies across time. Frankfurt: Campus Verlag.

Held, T. (1986). Institutionalisation and De-Institutionalisation of the Life Course. Human Development 29: 157-162.

Imhof, A. E. (1984). Die Lebenszeit. Vom aufgeschobenen Tod und von der Kunst des Lebens. Beck, München.

Imhof, A. E. (1986). Life-Course Patterns of Women and Their Husbands. $16^{\text {th }}$ to $20^{\text {th }}$ Century. in: A. B. Sørensen, F. E. Weinert \& L. R. Sherrod (eds.), Human devel- 
opment and the life course: multidisciplinary perspectives. Erlbaum, Hillsdale, 247270.

Kemper, T. (2011). Status, Power and Ritual Interaction: A Relational Reading of Durkheim, Goffman and Collins. Palgrave-Macmillan, Ashgate.

Kohli, M. (2003). Der institutionalisierte Lebenslauf: ein Blick zurück und nach vorn. in: J. Allmendinger (Hrsg.), Entstaatlichung und soziale Sicherheit. Verhandlungen des 31. Kongresses der DGS. Leske+Budrich, Opladen, 525-545.

Kohli, M. (1985). Die Institutionalisierung des Lebenslaufs. Historische Befunde und theoretische Argumente. Kölner Zeitschrift für Soziologie und Sozialpsychologie 37(1): 1-29.

Krüger, H. (2001). Geschlecht, Territorien, Institutionen. Beitrag zu einer Soziologie der Lebenslauf-Relationalität. in: C. Born \& H. Krüger, (eds.), Individualisierung und Verflechtung. Geschlecht und Generation im deutschen Lebenslaufregime. München: Juventa, 257-299.

Krüger, H. \& Levy, R. (2001). Linking Life Courses, Work, and the Family: Theorising a not so Visible Nexus between Women and Men. Canadian Journal of Sociology 26(2), 145-166.

Le Goff, J.-M. \& Levy, R. (eds., 2016). Devenir parents : devenir inégaux. Transition à la parentalité et inégalités de genre. Seismo, Zurich.

Leisering, L. (2003). Government and the Life Course. in: T. Mortimer \& M. Shanahan (eds.), Handbook of the Life Course. Kluwer Academic Press, New York, 205-225.

Lévi-Strauss, C. (1962). La pensée sauvage. Plon, Paris.

Levy, R. (2007). Particulière, singulière ou ordinaire ? La régulation suisse des parcours de vie sexués. in : T. Eberle \& K. Imhof (eds.). Sonderfall Schweiz. Seismo, Zurich 2007, 226-247. (Modified version reprinted as: Regulated life courses: na- 
tional regimes of gendered trajectories. in: R. Levy \& E. D. Widmer (2013, eds.). Gendered life courses between standardization and individualization - A European approach applied to Switzerland. LIT Verlag, Wien, 225-242).

Levy, R., Widmer, E. D., \& Kellerhals, J. (2002). Modern Families or Modernized Family Traditionalism? Master Status and the Gender Order in Switzerland. $\begin{array}{lllll}\text { Electronic Journal of } & \text { Sociology, }\end{array}$ http://www.sociology.org/content/vol006.004/lwk.html?PHPSESSID=f1dfc4b a3dfcb68ff77ab3efbb980e1c.

Levy, R., Ghisletta, P., Le Goff, J.-M., Spini, D. \& Widmer, E. D. (2005, eds.). Towards an Interdisciplinary Perspective on the Life Course. (Advances in Life Course Research 10). Elsevier, Amsterdam, Boston etc..

Levy, R. \& Widmer, E. D. (2013, eds.). Gendered life courses between standardization and individualization. A European approach applied to Switzerland. LIT Verlag, Wien.

Lewin, K. (1951). Field Theory in Social Science. Harper Bros., New York.

Liebig, B. \& Levy, R. (2015). Critical Transitions: The Production of Gender (In-) Equality in the Life Course. Introduction to the Special Issue with that title of Equality, Diversity and Inclusion: An International Journal 34(2).

Liebig, B., Levy, R., Sauer, B., \& Sousa-Poza, A. (2014). Gender Equality Policies in Switzerland: Institutional Factors of Success and Failure. Introduction to the Special Issue. Swiss Journal of Sociology, 40(2), 169-174.

Macmillan, Ross. (2005). The structure of the life course: Classic issues and current controversies. In: Ross Macmillan (ed.), The Structure of the Life Course: Individualized? Stanardized? Differentiated? Advances in Life Course Research 9, 3-24.

Mannheim, K. (1928). Das Problem der Generationen. Kölner Vierteljahreshefte für Soziologie 7, 157-185 et 309-330. 
Marshall, V. (2010). Agency and social structure in aging and life course research. in:

D. Dannefer and C. Phillipson (eds.), International Handbook of Social Gerontology. Sage, London, 294-305.

Martin, J. L. (2003). What Is Field Theory? American Journal of Sociology, 109(1): 1-49.

Mayer, K. U. (2003). The Sociology of the Life Course and Life Span Psychology - Diverging or Converging Pathways? in: Ursula M. Staudinger \& Ulman Lindenberger (eds.), Understanding Human Development: Lifespan Psychology in Exchange with Other Disciplines. Kluwer, Dordrecht, 463-481.

Mayer, K. U. (2001). Soziale Mobilität und Erwerbsverläufe in der Transformation Ostdeutschlands. in: W. Schluchter \& P. E. Quint (Hrsg.), Der Vereinigungsschock. Velbrück Wissenschaft, Weilerswist, 336-365.

Mayer, K. U., \& Schoepflin, U. (1989). The state and the life course. Annual review of sociology, 187-209.

Mitchell, B. A. (2003), Life Course Theory. in: International Encyclopedia of Marriage and the Family. consulted 5.10.2014 on http://www.encyclopedia.com/doc/1G2-3406900275.html

Moen, P. (ed., 2003). Its about time. Couples and careers. Cornell University Press, Ithaka N.Y.

Moen, P., \& Sweet, S. (2004). From "Work-Family" to "Flexible-Careers". A Life Course Reframing. Community, Work \& Family 7(2), 209-226.

Moen, P., Dempster-McCain, D., \& Williams, R. M. (1992). Successful Aging: A LifeCourse Perspective on Women's Multiples Roles and Health. American Journal of Sociology 97(6), 1612-1638.

Mortimer, J. T., \& Shanahan, M. J. (eds.). (2006). Handbook of the life course. Amsterdam: Springer. 
Müller, N. S., Sapin, M., Gauthier, J.-A., Orita, A., and Widmer, E. D. (2013). Psychiatric troubles - life-course disorders? Exploring the life trajectories of individuals under psychotherapy. in: R. Levy \& E. D. Widmer (eds.), Gendered life courses between standardization and individualization - A European approach applied to Switzerland. LIT Verlag, Wien, 209-224.

Neugarten, B., Moore, J. W., \& Lowe, J. C. (1965). Age Norms, Age Constraints, and Adult Socialization. American Journal of Sociology 70(6), 710-717.

Neveu, É. (2013). Les sciences sociales doivent-elles accumuler les capitaux? Revue française de science politique, 63(2), 337-358.

O'Rand, A. (1995). The Cumulative Stratification of the Life Course. in: Binstock, R. H., \& George, L. K. (eds.), Handbook of Aging and the Social Sciences. Academic Press, San Diego, 188-207.

Pallas, A. M., \& Jennings, J. L. (2009). Cumulative Knowledge about Cumulative Advantage. Swiss Journal of Sociology, 35(2), 211-229.

Palloni, A., Massey, D. S., Ceballos, M., Espinosa, K., \& Spittel, M. (2001). Social Capital and International Migration: A Test Using Information on Family Networks1. American Journal of Sociology, 106(5), 1262-1298.

Parin, P., Morgenthaler, F. \& Parin-Matthey, G. (1963). Die Weissen denken zuviel. Ethnopsychoanalytische Untersuchungen bei den Dogon in Westafrika. Atlantis, Zurich.

Parsons, T., \& Bales, R. F. (1955). Family, Socialization and Interaction Process. Free Press, Glencoe.

Riano, Y., Limacher, K., Aschwanden, A., Hirsig, S., \& Wastl-Walter, D. (2015). Shaping Gender Inequalities: Critical Moments and Critical Places. Equality, Diversity and Inclusion: An International Journal 34(2), 2015. 
Riley, M. W., Johnson, M. E. \& Foner A. (1972). Aging and Society, vol. III - A Sociology of Age Stratification. Russell Sage, New York.

Rodin, J., Schooler, C., \& Schaie, K. W. (1990, eds.), Self-directedness: Cause and Effects throughout the Life Course. Erlbaum, Hillsdale.

Samuel, Y., and Yuchtman-Yaar, E. (1979). The Status and Situs Dimensions as Determinants of Occupational Attractiveness. Quality \& Quantity 13(6), 485-501.

Savage M., Warde A., \& Devine F. (2005). Capitals, assets, and resources: some critical issues1. The British Journal of Sociology, 56(1), 31-47.

Schütz, A., and Luckmann, T. (1973). The Structures of the Lifeworld. Northwestern University Press, Evanston.

Settersten Jr., R. A. (2003). Age structuring and the rhythm of the life course (pp. 81-98). Amsterdam: Springer.

Settersten, R. A. (2009). It Takes Two to Tango: The (Un)easy dance between Lifecourse Sociology and Life-span Psychology. Advances in Life Course Research 14(1-2), 74-81.

Settersten, R. A., and Gannon, L. (2005). Structure, Agency, and the Space Between: On the Challenges and Contradictions of a Blended View of the Life Course. in : Levy, R., Ghisletta, P., Le Goff, J.-M., Spini, D., \& Widmer, E. D. (eds.), Towards an Interdisciplinary Perspective on the Life Course. (Advances in Life Course Research 10), Elsevier : Amsterdam, Oxford, 35-55.

Shanahan, M. J., \& MacMillan, R. (2008). Biography and the Sociological Imagination. Norton, New York.

Sorokin, P. (1959). Social and Cultural Mobility. Free Press of Glencoe, New York.

Spini, D., Hanappi, D., Bernardi, L., Oris, M., and Bickel, J.-F. (2013). Vulnerability across the life course: a theoretical framework and research directions. LIVES Working Paper 27, Lausanne (retrieved on 23.12.2014, http://www.lives- 
nccr.ch/sites/default/files/pdf/publication/27_lives_wp_spini_vulnerability. pdf)

Strandh, M., Winefield, A., Nilsson, K., and Hammarström, A. (2014). Unemployment and mental health scarring during the life course. European Journal of Public Health 24(3), 440-445.

van Oorschot, W. (2005). The social capital of European welfare states: the crowding out hypothesis revisited. Journal of European Social Policy 15(1), 5-26.

Weber, M. (1972). Wirtschaft und Gesellschaft. Mohr/Siebeck, Tübingen.

Widmer, E. D., \& Ritschard, G. (2009). The de-standardization of the life course: Are men and women equal? Advances in Life Course Research, 14(1), 28-39. 